\title{
ARTIGO INDEFINIDO E NUMERAL
}

\author{
António José Sandmann *
}

\section{Aspectos diacrónicos.}

Embora o latim clássico nāo possuísse propriamente artigo, o numeral unus. segundo mostra Ismael de Lima Coutinho, 1 começava a desempenhar, aqui c ali, a função de artigo indefinido. sendo já mais freqüente seu uso no latim popular. Hoje é fato geral nas línguas românicas e nas do ramo anglo-germânico. como o inglês e o alemão, por exemplo.

A evoluçāo fonética do latim unu para o português um obedece a regras gerais: de unu temos uu, por síncope da consoante nasal dental $n$ e nasalizacão da vogal aue a vrecedia: uu. oela natural aversāo ao hiato, simplifica-se para $u$, escrito hoje um.

Já o feminino apresenta uma complexidade maior, que é o aparecimento do $m$ de uma. Ismael de Lima Coutinho invoca a explica. ção de Leite de Vasconcelos, segundo o qual o m teria aparecido em uma como o nh em vinho, etc., o que scria um fato isolado.

Silveira Bueno, 2 pelo fato mesmo de ser um caso isolado, adota, para explicá-lo. a tese da influência da grafia: $\mathbf{u a}$, pronunciado $\mathbf{u - a}$, foi à semelhança de $\tilde{u}$, também escrito um, grafado uma, pronunciado, ain.da de início, um-a e depois $\mathbf{u}$-ma, com $\mathbf{m}=$ consoante nasal bilabial".

1 COUTINHO. Ismael de Limn. Gramattes histórica. 6. ed. Rio de Ja neiro, Academica, 1971 . p. 252.

2 SILVEIRA BUENo, Francisco da. Formasăo histórten da lingua portuguesa. 2. ed. Rio de Janeiro, Acadêmica, 1958.

- O autor licenciou-se em Letras Anglo-Germanicas, em 1961, pela Univergidade Federal do Parana. Em Marburgo (Alemanha), estudou Teoria Literarla a Língun e Literatura Alema (1960). Publicou o morfema de grau - sufixo flexional ou derivactonal na revista Letras (n० 20, 1972) e Em torno da rogal temática em Arquivos (v. 1, no 5, 1972). Atualmente, exerce as funçoes de Auxiliar de Ensino de Lingua Portuguesa na Universidade Federal do Paraná. 
2. A categoria gramatical de número.

O numeral um, uma, indicando a unidade, a quantidade unitária, nāo pode naturalmente reccber flexāo numérica de plural. Nāo assim o artigo, que sc adapta ao nome que determina também cm número. Originário do numeral, como se mostrou acima, o qual nāo tem flexāo de número plural, foi preciso que para o artigo se criasse um plural. A analogia morfológica explica facilmente essa inovação. O s, morfema de plural dos nomes do portuguès, é adicionado a um c uma, formando uns e umas.

\section{A distribulção.}

Também quanto à distribuição diferem o numeral e o artigo in. definido. Um, uma, numeral, entra no paradigma de dois, três quatro, etc. Um, uma, uns, umas, artigo, entra no paradigma de o, a, os, as, artigo indefinido.

Em Achei um anel, um, artigo indefinido e que indetermina o objeto anel, está em oposiçāo a o de Achel o anel, em que o artigo definido o determina o objeto anel, que seria, $\mathrm{p}$. ex., aquele anel que eu perdi e estava procurando.

Em Tenho um anel, um, numeral, tal será se estiver em oposição a Tenho dois anéis, ou três, quatro, etc. Mas como saber que um em Tenho um anel, é numeral $\mathfrak{e}$ não artigo? A resposta nos dá a intensi. dade, a ser vista no item seguinte.

\section{A intensidade.}

A diferença maior, porém, entre um, artigo, e um, numeral, pa. rece estar na intensidade. Tanto um como outro são vocábulos mór. ficos porque elementos móvcis, separáveis das palavras que determinam. Achei um anel, em que afirmávamos que um é artigo indefeni. do, permite a inserçāo de outro elemento entre um e anel: Achel um bonito anel. $O$ mesmo se pode fazer em Tenho um anel, em que admitíamos ser um numeral: Tenho um só anel.

Um, artigo indefinido, no entanto, nāo é vocábulo fonológico, cumo o é o numeral. Segundo a doutrina de Joaquim Mattoso Cáma. ra $\mathrm{Jr}_{1}, 3$ a pauta acentual de Achel um anel é 13114 , como seria a de Achei o anel. A de Tenho um anel é 1321 , como seria a de Tenho dois anéis. Se admitirmos com Mattoso Câmara que vocábulo fonológico é aquele que, dentro do grupo de força, tem, no minimo, intensidade 2 ,

3 MATtoso CAMara JR., Joaquim. Estrutura da lingua portuguesa. 2 . ed. Petrópolis, Vozes. 19i0. p. 53. 
só estilisticamente ou por uma pausa inesperada após o artigo este poderia receber essa intensidade, e assumir, pois, "status" de vocábulo fonológico, caso $\mathrm{cm}$ que teríamos de recorrer à distribuição em paradigmas para diferençar o artigo do numeral.

O não ser o artigo um vocábulo fonológico, mas ter csse "status" o numeral, ć comprovado por mais um fato. Sc à afirmação Achel um anel se fizer a pergunta $O$ que você achou?, a resposta será Um anel. Feita a pergunta Quantos anéls você tem? à afirmação Tenho um anel, a resposta será Um. Veja-se a diferença: o artigo indefinido, porque palavra clítica, por não ser vocábulo fonológico, não pode ocorrer sozinho, fato perfeitamente possivel com o numeral.

\section{REFHRENCIAS BIBLIOGRAFICAS}

COUTINHo, Ismacl de Lima. Grnmätica historlea. 6. ed. Rlo de Janelro, Academl. ca, 1971. 357 p.

MatToso Camara JR., Joaquim. Estrutura du lingun portuguesa, 2. ed. Petró. polls, Vozes, 1970. $114 \mathrm{~J}$.

SILverra BUENo. Francisco da. Formacĩo histórica da lingua portuguesa. 2. cd. Rio de Janeiro, Académica, 1958. $322 \mathrm{p}$.

\section{Resumo.}

0 artigo indefinido um originou-se do numeral latino unu, língua em que este só esporadicamente funcionava como artigo. Diverge-se sobre o aparecimento da nasal bilabial no feminino uma. Explica-o, mais provavelmente, a orafia de $\overrightarrow{\mathbf{u}-a}$. aue também se escrevia um-a

Quanto à categoria gramatical de númcro plural só o artigo a possui, porque o numeral, indicando a unidadc, a quantidade unitária, não pode ter plural.

Se se considerar a distribuição em paradigmas, aparece outra diferença entre o numeral e o artigo: cste está $\mathrm{cm}$ oposição ao artigo definido o, e aquele, a dols, três, quatro, etc.

A maior diferença está, porém na intensidade com que são pro. nunciados. O artigo não tem "status" de vocábulo fonológico porque de intensidade 1 . O numeral o tem, porque de intensidade 2. Nas respostas, por outro lado, o numeral ocorre sozinho, formando frase. Não assim o artigo.

\section{Summary}

The indefinite article um comes from the Latin numeral unu, in which language it was seldom used as an article. The opinions about the origin of the $\mathbf{m}$, in the feminin uma, diverge. The cause is probably the form of writing $\tilde{u}-a$, written also um-a. 
Only the article has a plural: uns, umas. The numeral, which indicates the unitarian quantity, cannot, logically, have the plural form.

If one considers the paradigmatic distribution, another difference between the article um and the numeral um appears: um, indefinite article, is in opposition to the definite article 0 , while the numeral is in opposition to dols (two), très (three), quatro (four), etc.

The greatest difference, however, is in the accent. The article does not have the "status" of a phonological word (vocábulo fonológico), because it has the accent 1 . The numeral is a phonological word, because it has the accent 2 or 3 . Moreover, in the answers, the numeral may be alone, form a sentence, not so the article. 